is not typical of an area of vascular supply. The alcohol would not be able to evaporate if the baby is lying on it, and the underlying surface would therefore act as an occlusive dressing. The site of the lesions suggests that the cleansing solution drips down to soak the surface on which the baby is lying. Püschel ${ }^{8}$ recently reported a case of percutaneous alcohol intoxication in a 2-year-old child when alcohol-soaked bandages were applied to damaged skin. The child showed features of alcohol intoxication and developed haemorrhagic skin lesions.

The use of alcoholic solutions to clean the skin of immature babies is potentially dangerous. This report is a reminder that great care must be taken if pharmacologically active agents are applied to immature skin.

\footnotetext{
References

1 Kagan B M, Mirman B, Calvin J, Lundeen E. Cyanosis in premature infants due to aniline dye intoxication. J Pediatr 1949; 34: 574-8.
}

2 Curley A, Hawk R E, Kimbrough R D, Nathenson G, Finberg L. Dermal absorption of hexachlorophane in infants. Lancet 1971; ii: 296-7.

3 Mann N P. Gluteal skin necrosis after umbilical artery catheterisation. Arch Dis Child 1980; 55: 815-7.

4 Wilkinson A R, Baum J D, Keeling J W. Letter: Superficial skin necrosis in babies prepared for umbilical arterial catherisation. Arch Dis Child 1981 ; 56: 237-8.

5 Powell H, Swarner O, Gluck L, Lampert P. Hexachlorophene myelinopathy in premature infants. $J$ Pediatr 1973; 82: 976-81.

6 Chabrolle J P, Rossier A. Goitre and hypothyroidism in the newborn after cutaneous absorption of iodine. Arch Dis Child 1978; 53: 495-8.

7 Cowen J, Ellis S H, McAinsh J. Absorption of chlorhexidine from the intact skin of newborn infants. Arch Dis Child 1979; 54: 379-83.

8 Püschel K. Percutaneous alcohol intoxication. Eur $J$ Pediatr 1981 ; 136: 317-8.

Correspondence to Dr N Rutter, Department of Neonatal Medicine and Surgery, City Hospital, Hucknall Road, Nottingham NG5 1PD.

Received 23 February 1982

\title{
Debendox does not cause the Poland anomaly
}

\author{
T J DAVID \\ Department of Child Health, University of Manchester
}

SUMMARY The suggestion that Debendox may cause the Poland anomaly is refuted by a study of the antenatal drug exposure in 46 cases of the Poland anomaly and 32 cases of isolated absence of the pectoralis major. Debendox had been prescribed in one case of the Poland anomaly and in one case of isolated pectoralis absence, but in neither was the compound given during organogenesis. In none of the 78 cases could Debendox be causally implicated.

The Poland anomaly is a rare congenital malformation comprising unilateral absence of the pectoralis major muscle with an ipsilateral hand defect. Isolated absence of the pectoralis major may be a related malformation, and the two conditions possibly represent a spectrum of defects.

Debendox is an antiemetic drug used in pregnancy. It is a combination of dicyclomine hydrochloride $10 \mathrm{mg}$, doxylamine succinate $10 \mathrm{mg}$, and pyridoxine $10 \mathrm{mg}$. It has been marketed in the UK since 1958. It has been specifically suggested that Debendox may cause the Poland anomaly. ${ }^{12}$ In a recent study of Debendox and limb reduction deformities, ${ }^{3}$ out of 40932 births there were 15 cases of limb reduction deformities. In only 3 was there a history of first trimester Debendox exposure, but in 2 of them the limb reduction deformity was the Poland anomaly. In the remaining 12 cases of limb reduction defects without first trimester exposure to Debendox there were no cases of the Poland anomaly.

In view of the specificity of teratogens, notably thalidomide, it was decided to pursue a specific causal relationship between the Poland anomaly, the related defect of isolated pectoralis absence, and the use of Debendox in pregnancy.

\section{Materials and methods}

Since 1970, a study of the aetiology of the Poland anomaly has been in progress. Cases were referred to me by paediatricians and plastic surgeons who know of my interest in it, but were not selected in any way. All cases were seen before it had been suggested $^{1}$ that Debendox might cause the Poland anomaly. A special examination of the mother's antenatal drug exposure was made in each case. The patients comprise two groups (1) 32 cases with isolated pectoralis major absence, and (2) 46 cases with the Poland anomaly. All cases were examined 
Table Year of conception

\begin{tabular}{lcl}
\hline Year & Poland anomaly & Isolated pectoralis absence \\
\hline $1891-1920$ & 3 & 1 \\
$1921-1930$ & 1 & 2 \\
$1931-1940$ & 4 & 2 \\
$1941-1950$ & 2 & 4 \\
$1951-1957$ & 4 & 3 \\
$1958-1962$ & 5 & 3 \\
$1963-1967$ & 10 & 3 \\
$1968-1972$ & 9 & 9 \\
$1973-1977$ & 8 & 5 \\
\hline
\end{tabular}

by me. Details of each mother's antenatal drug exposure were verified by examining the mother's hospital antenatal records and by obtaining details of drug prescription from the family doctor. This report is solely concerned with Debendox and not with any other drugs or possible teratogens. The year of conception was estimated in each case. All but 2 patients were born in England and Wales, and most were living in the south or south west (Table).

\section{Results}

Drug ingestion in pregnancy. Details of drug ingestion during pregnancy could not be obtained in 6 cases born before 1924. Debendox had been prescribed in 2 of the remaining 72 cases, and details of these two cases are given below.

\section{Case 1}

Age 10 years; born 28.11.70; isolated pectoralis absence

First pregnancy of 18-year-old mother. Father a 21-year-old heroin addict. Mother had an adenotonsillectomy a few days after the estimated date of conception. Debendox, two tablets at bedtime, had been prescribed for vomiting at 12 and 14 weeks' post-conception, and taken for 4 weeks. Delivery at 39 weeks, birthweight $1.42 \mathrm{~kg}$. Absence of the sternocostal and clavicular heads of the right pectoralis major was noted at birth. In addition, the child had a lumbar meningocele with an intramedullary teratoma, and hydrocephalus. The arms and hands were normal.

\section{Case 2}

Age 3 years; born 24.9.77; Poland anomaly

First pregnancy of 31-year-old mother. Debendox, two tablets at bedtime, had been prescribed for nausea 4 weeks' after conception, but the mother when interviewed shortly after birth and 3 years later said the tablets had been taken only for a few days. Delivery at 40 weeks, birthweight $3.36 \mathrm{~kg}$.
The child had an absent sternocostal head of the right pectoralis major muscle, a hypoplastic right forearm, shortening of all 4 fingers on the right hand, with partial cutaneous syndactyly of the index and middle finger, and shortening of the flexor tendons to the middle finger.

\section{Discussion}

Twenty-six (14 Poland anomaly; 12 isolated pectoralis absence) cases were conceived before 1958, the year in which Debendox was introduced into the UK, and these cases could not have been caused by the drug. The critical period of embryogenesis for the Poland anomaly, which presumably also applies to isolated pectoralis absence, has been estimated to be $44-48^{1}$ or 43-46 days ${ }^{4}$ after conception. Therefore Debendox was taken well after the critical period in the first case, and well before the critical period in the second case. The larger number of cases conceived after 1963 is an ascertainment artefact, and is due to the fact that most cases were children referred by paediatricians.

A drawback to this study is that it is retrospective and there is no control group. It would be extremely difficult to obtain a control group in view of the fact that the cases span a 90 -year period. The rarity of the defect makes a prospective study of a large number of cases impossible. Furthermore, it is not known how representative a sample of cases this is, either in terms of a geographical area or the general (as opposed to the hospital) population. Nevertheless, despite these theoretical disadvantages, in none of the 46 cases of the Poland anomaly or 32 cases of isolated pectoralis absence was there any evidence that Debendox could have caused the defect.

I thank Professor R D H Boyd for constructive criticism and Mrs C Webb for typing the manuscript.

\section{References}

1 Mellor S. Letter: Fetal malformation after Debendox treatment in early pregnancy. $\mathrm{Br}$ Med J 1978; i : 1055.

2 Brent R L. Drugs as teratogens. The Bendectin saga: another American tragedy (abstract). Teratology 1981; 23: $28 \mathrm{~A}$.

3 Correy J F, Newman N M. Debendox and limb reduction deformities. Med J Aust 1981; i: 417-8.

4 Goldberg M J, Mazzei R J. Poland syndrome: a concept of pathogenesis based on limb bud embryology. Birth Defects 1977; 13: 103-15.

Correspondence to Dr T J David, Department of Child Health, Booth Hall Children's Hospital, Charlestown Road, Blackley, Manchester M9 2AA.

Received 23 February 1982 